\title{
High prevalence of antinuclear antibodies and lupus anticoagulant in patients hospitalized for SARS-CoV2 pneumonia
}

\author{
Carmine Gazzaruso ${ }^{1,2}$ (D) $\cdot$ Nicoletta Carlo Stella ${ }^{3} \cdot$ Giuseppe Mariani $^{3} \cdot$ Carlo Nai $^{3} \cdot$ Adriana Coppola $^{2}$. \\ Daniela Naldani ${ }^{4} \cdot$ Pietro Gallotti ${ }^{3}$
}

Received: 2 May 2020 /Revised: 2 May 2020 / Accepted: 15 May 2020 / Published online: 27 May 2020

(C) International League of Associations for Rheumatology (ILAR) 2020

\begin{abstract}
About $15-20 \%$ of patients with severe acute respiratory syndrome-coronavirus 2 (SARS-CoV2) disease experience pneumonia of variable extent and course [1]. A proportion of them have cardiovascular involvement, including myocarditis, ischemia and shock, and thrombotic disease, including venous thromboembolism, pulmonary embolism (PE), and disseminated intravascular coagulation, that can lead to death [2]. Systemic inflammation and a procoagulant state play a major pathophysiological role in these severe forms and correlate very well with disease severity and death [2]. It is unclear whether the procoagulant profile is a direct effect of infection or whether it is a consequence of inflammation [2]. Autoimmune diseases are characterized by inflammation and some of them by a procoagulant state; moreover, several viruses are involved in their development [3]. An autoimmune mechanism mediated by antiphospholipid antibodies has been suggested to explain the procoagulant state in SARS-CoV2 disease [4], but the impact of autoimmune mechanisms on SARS-CoV2 disease was never studied. The aim of our study was to evaluate markers of autoimmunity in patients hospitalized for SARS-CoV2 pneumonia.

A panel of autoimmune markers was evaluated in 45 consecutive patients admitted to our hospital for SARS-CoV2
\end{abstract}

Carmine Gazzaruso

c.gazzaruso@gmail.com

1 Emergency Unit and Endocrinology Unit, Istituto Clinico "Beato Matteo" (Hospital Group San Donato), Corso Pavia, 84, 27029 Vigevano, Italy

2 Centre for Applied Clinical Research (Ce.R.C.A.), Istituto Clinico "Beato Matteo" (Hospital Group San Donato), Vigevano, Italy

3 Internal Medicine, Oncology and Rheumatology Unit, Istituto Clinico "Beato Matteo" (Hospital Group San Donato),

Vigevano, Italy

4 Clinical Pathology, Istituto Clinico "Beato Matteo" (Hospital Group San Donato), Vigevano, Italy pneumonia. Pneumonia was documented by computed tomography and infection was established by RT-PCR. Blood samples were taken on admission. Statistical analysis was performed with $t$ test after log-transformation for non-normally distributed variables and with exact Fisher test for frequency comparisons.

Table 1 shows features of the patients, prevalence of autoimmune markers, and features of the patients stratified by presence/absence of ANA and lupus anticoagulant. Several autoimmune markers were present. The prevalence of antinuclear antibodies (ANA) (35.6\%) and lupus anticoagulant $(11.1 \%)$ was very high. Moreover, borderline values of lupus anticoagulant were present in a high percentage of subjects $(35.5 \%)$. No difference was found between subjects with positive and those with borderline lupus anticoagulant, so we grouped the two together in our analysis.

The high prevalence of ANA, together with other autoimmune markers, suggests an involvement of autoimmune mechanisms in SARS2-CoV2 disease. In addition, lupus anticoagulant may be associated with the increased thrombotic risk described in a high proportion of patients and characterized by cardiac involvement, respiratory complications, and death [2]. The prevalence of lupus anticoagulant in our patients is similar to that recently reported [5]: indeed, if we group together subjects with positive and those with borderline values of lupus anticoagulant, the prevalence becomes impressively high (46.6\%). On the other hand, we cannot exclude that borderline values of lupus anticoagulant early detected on admission will become positive in a subsequent short time. No significant differences in C-reactive protein, D-dimer, prothrombin time, and activated partialthromboplastin time were observed between subjects with and without ANA or lupus anticoagulant. The lack of difference in D-dimer between patients with and without lupus anticoagulant may be surprising, but this may be due to the fact that inflammation can affect D-dimer levels and that our study population is relatively small. The significant 
Table 1 Features of patients with SARS-CoV2 pneumonia, prevalence of autoimmune markers, and features of the patients stratified by presence/absence of ANA and lupus anticoagulant

\begin{tabular}{|c|c|c|c|}
\hline \multicolumn{4}{|l|}{ Variable } \\
\hline \multicolumn{2}{|l|}{ Age (years) } & \multicolumn{2}{|l|}{$66.1 \pm 12.5$} \\
\hline \multicolumn{2}{|l|}{ Men $(\%)$} & \multicolumn{2}{|l|}{80} \\
\hline \multicolumn{2}{|l|}{ C-reactive protein $(\mathrm{mg} / \mathrm{L})$} & \multicolumn{2}{|l|}{$174.2 \pm 95.7$} \\
\hline \multicolumn{2}{|l|}{$\mathrm{D}$-dimer $(\mathrm{ng} / \mathrm{ml})$} & \multicolumn{2}{|l|}{$2854 \pm 7495.2$} \\
\hline \multicolumn{2}{|l|}{ Ultra-sensitivity cardiac troponin (pg/ml) } & \multicolumn{2}{|l|}{$48.6 \pm 86.6$} \\
\hline \multicolumn{2}{|l|}{ Prothrombin time $(\mathrm{sec})$} & \multicolumn{2}{|l|}{$12.1 \pm 1.6$} \\
\hline \multicolumn{2}{|l|}{ Activated partial-thromboplastin time (sec) } & \multicolumn{2}{|l|}{$30.3 \pm 4.1$} \\
\hline \multicolumn{2}{|l|}{ Oxygen saturation (\%) } & \multicolumn{2}{|l|}{$88.1 \pm 6.7$} \\
\hline \multicolumn{2}{|l|}{ Complement C3 (mg/dl) } & \multicolumn{2}{|l|}{$148.4 \pm 41.5$} \\
\hline \multicolumn{2}{|l|}{ Complement C4 (mg/dl) } & \multicolumn{2}{|l|}{$30.5 \pm 15.0$} \\
\hline \multicolumn{2}{|l|}{ ANA $(\%)$} & \multicolumn{2}{|l|}{35.6} \\
\hline \multicolumn{2}{|l|}{$\begin{array}{l}\text { ENA (anti RNP; anti Scl70, } \\
\text { anti Sm, anti SS-A/Ro52; } \\
\text { anti SS-A/Ro60; anti SS-B/La) (\%) }\end{array}$} & \multicolumn{2}{|l|}{4.4 (anti SS-A/Ro52) } \\
\hline \multicolumn{2}{|l|}{ p-ANCA c-ANCA (\%) } & 6.6 & \\
\hline Anti MPO (\%) & & 2.2 & \\
\hline Anti PR3 (\%) & & 0 & \\
\hline Anticardiolipin IgM (\%) & & 2.2 & \\
\hline Anticardiolipin IGG (\%) & & 2.2 & \\
\hline Anti-beta2-glycoprotein IgM (\%) & & 2.2 & \\
\hline & & 4.4 (borderline) & \\
\hline Anti beta2-glycoprotein IgG (\%) & & 4.4 (borderline) & \\
\hline Lupus anticoagulant $(\%)$ & & 11.1 & \\
\hline & & 35.5 (borderline) & \\
\hline Variable & Patients with positive ANA $(n=16)$ & Patients with negative ANA $(n=29)$ & $p$ value \\
\hline Age (years) & $68.5 \pm 13.4$ & $64.7 \pm 12.0$ & 0.3372 \\
\hline Men $(\%)$ & 75 & 82.8 & 0.6998 \\
\hline C-reactive protein $(\mathrm{mg} / \mathrm{L})$ & $184.9 \pm 108.2$ & $168.3 \pm$ & 0.7593 \\
\hline D-dimer (ng/ml) & $1821.2 \pm 1742.3$ & $3424.1 \pm 9257.8$ & 0.6815 \\
\hline $\begin{array}{l}\text { Ultra-sensitivity cardiac troponin } \\
(\mathrm{pg} / \mathrm{ml})\end{array}$ & $48.5 \pm 100.1$ & $48.6 \pm 80.2$ & 0.1522 \\
\hline Prothrombin time (sec) & $12.3 \pm 1.6$ & $11.9 \pm 1.6$ & 0.3823 \\
\hline $\begin{array}{l}\text { Activated partial-thromboplastin time } \\
(\mathrm{sec})\end{array}$ & $30.2 \pm 4.7$ & $30.3 \pm 3.7$ & 0.9021 \\
\hline Oxygen saturation (\%) & $88.1 \pm 5.5$ & $88.1 \pm 7.4$ & 0.9329 \\
\hline Lupus anticoagulant (\%) & 50 & 44.8 & 0.7648 \\
\hline Variable & $\begin{array}{l}\text { Patients with positive or borderline lupus anticoagulant } \\
\quad(n=21)\end{array}$ & $\begin{array}{l}\text { Patients with negative lupus anticoagulant } \\
\quad(n=24)\end{array}$ & $p$ value \\
\hline Age (years) & $69.2 \pm 12.9$ & $63.3 \pm 11.7$ & 0.1118 \\
\hline Men $(\%)$ & 85.7 & 75 & 0.4689 \\
\hline C-reactive protein $(\mathrm{mg} / \mathrm{L})$ & $200.3 \pm 99.2$ & $151.3 \pm 88.3$ & 0.0868 \\
\hline D-dimer (ng/ml) & $2006.9 \pm 2665.6$ & $3595.6 \pm 10,003.1$ & 0.6172 \\
\hline $\begin{array}{l}\text { Ultra-sensitivity cardiac troponin } \\
(\mathrm{pg} / \mathrm{ml})\end{array}$ & $82.9 \pm 115.8$ & $18.5 \pm 25.6$ & 0.0025 \\
\hline Prothrombin time (sec) & $12.0 \pm 1.3$ & $12.1 \pm 1.8$ & 0.7883 \\
\hline $\begin{array}{l}\text { Activated partial-thromboplastin time } \\
(\mathrm{sec})\end{array}$ & $31.1 \pm 4.5$ & $29.6 \pm 3.5$ & 0.2139 \\
\hline Oxygen saturation (\%) & $85.8 \pm 7.6$ & $90.1 \pm 5.6$ & 0.0336 \\
\hline ANA $(\%)$ & 38.1 & 33.3 & 0.7648 \\
\hline
\end{tabular}

SARS-CoV2, severe acute respiratory syndrome-coronavirus 2; ANA, antinuclear antibodies; ENA, extractable nuclear antigen; anti RNP: antiribonucleoprotein; anti Sm, anti Smith; anti Scl70, anti-scleroderma; anti SS-A, anti Sjögren's syndrome A; anti SS-B, anti-Sjögren's syndrome B; $p$ $A N C A$, perinuclear antineutrophil cytoplasmic antibodies; $c-A N C A$, cytoplasmatic antineutrophil cytoplasmic antibodies; anti MPO, antimyeloperoxidase; anti $P R 3$, anti proteinase 3

association of both cardiac troponin and oxygen saturation with lupus anticoagulant may be of clinical interest, as it may predict a worse course of pneumonia, characterized by thrombotic complications and death. However, specific studies have to confirm this hypothesis. In conclusion, our data suggest a possible role of autoimmune mechanisms in
SARS-CoV2 pneumonia requiring hospitalization and this may imply specific treatments. Other studies should clarify whether lupus anticoagulant can be used to stratify patients at high risk for cardiovascular involvement and thrombosis and whether it can predict poorer outcomes of viral pneumonia, including death. 
Author contributions CG and PG contributed to concept, design and supervision of the study, interpretation of data, and writing the manuscript. CG and AC performed statistical analysis. NCS, GM, CN, AC, and DN contributed to the acquisition and interpretation of data and critical revision of the manuscript.

\section{Compliance with ethical standards}

Disclosures None.

\section{References}

1. Di Gennaro F, Pizzol D, Marotta C et al (2020) Coronavirus diseases (COVID-19) current status and future perspectives: a narrative review. Int J Environ Res Public Health 17(8):E2690. https://doi.org/ 10.3390/ijerph17082690

2. Bikdeli B, Madhavan MV, Jimenez D et al (2020) COVID-19 and thrombotic or thromboembolic disease: implications for prevention, antithrombotic therapy, and follow-up. J Am Coll Cardiol. https:// doi.org/10.1016/j.jacc.2020.04.031

3. Smatti MK, Cyprian FS, Nasrallah GK et al (2019) Viruses and autoimmunity: a review on the potential interaction and molecular mechanisms. Viruses 11(8):E762. https://doi.org/10.3390/ v11080762

4. Zhang Y, Xiao M, Zhang S, Xia P, Cao W, Jiang W, Chen H, Ding X, Zhao H, Zhang H, Wang C, Zhao J, Sun X, Tian R, Wu W, Wu D, Ma J, Chen Y, Zhang D, Xie J, Yan X, Zhou X, Liu Z, Wang J, du B, Qin Y, Gao P, Qin X, Xu Y, Zhang W, Li T, Zhang F, Zhao Y, Li Y, Zhang S (2020) Coagulopathy and antiphospholipid antibodies in patients with Covid-19. N Engl J Med 382(17):e38. https://doi.org/ 10.1056/NEJMc2007575

5. Harzallah I, Debliquis A, Drénou B (2020) Lupus anticoagulant is frequent in patients with Covid-19. J Thromb Haemost. https://doi. org/10.1111/jth.14867

Publisher's note Springer Nature remains neutral with regard to jurisdictional claims in published maps and institutional affiliations. 